\title{
The influence of particle size on seston deposition in streams
}

\author{
Steven A. Thomas ${ }^{1}$ \\ Department of Biological Sciences, Idaho State University, Pocatello, Idaho
}

\section{J. Denis Newbold}

Stroud Water Research Center, 512 Spencer Road, Avondale, Pennsylvania

\section{Michael T. Monaghan}

Department of Limnology, Swiss Federal Institute for Environmental Science and Technology (EAWAG/ETH), CH-8600 Dubendorf, Switzerland

\section{G. Wayne Minshall}

Department of Biological Sciences, Idaho State University, Pocatello, Idaho

\section{Theodore Georgian}

Department of Biology, Saint Bonaventure University, Saint Bonaventure, New York

\section{Colbert E. Cushing}

Department of Fishery and Wildlife Biology, Colorado State University, Fort Collins, Colorado

\begin{abstract}
We investigated how particle size influences deposition and transport of fine particulate organic matter in streams. Field additions of very fine (VFPOM, 15-52 $\mu \mathrm{m}$ ), fine (FPOM, 53-106 $\mu \mathrm{m}$ ), and medium (MPOM, 107-250 $\mu \mathrm{m}$ ) detritus and live diatoms (Asterionella sp.) were used to quantify the longitudinal loss rate $\left(k_{\mathrm{P}}\right)$ of each material type and to derive estimates of mean transport distance $\left(S_{\mathrm{P}}\right)$ and field deposition velocity $\left(v_{\mathrm{dep}}\right)$. In all experiments, smaller particles deposited more slowly, and thus traveled farther, than larger size classes. Significant differences in $k_{\mathrm{P}}$ were detected in four of seven paired FPOM and VFPOM particle additions. $v_{\text {dep }}$ estimates were neither equivalent nor closely associated with calculated quiescent water fall velocities $\left(v_{\text {fall }}\right)$ for all size classes. Variation in $S_{\mathrm{P}}$ and $v_{\text {dep }}$ of FPOM and VFPOM were strongly correlated across hydrological conditions $(r=0.94$ and 0.92 , respectively). Variation in $v_{\text {dep }}$ was poorly associated with physical attributes of the stream. Transport distances were positively associated with the cross-sectional area of the transient storage zone $\left(A_{\mathrm{S}}\right)$ and the uptake length of water $\left(S_{\mathrm{w}}\right)$ for both size classes. We argue that local hydrological and benthic conditions establish a minimum rate of particle deposition and that departures from this rate due to gravitational forces begin to occur at particle diameters similar to the larger size classes used in this study $(50-100 \mu \mathrm{m})$.
\end{abstract}

Fine particulate organic matter (FPOM, 53-106 $\mu \mathrm{m})$ often constitutes a large proportion of organic matter transported by streams (Naiman and Sedell 1979; Wallace et al. 1982; Minshall et al. 1983; Webster and Meyer 1997). FPOM movement in streams is envisioned as a series of transport

\footnotetext{
${ }^{1}$ Current address: Department of Biology, Virginia Polytechnic Institute and State University, Blacksburg, Virginia.

\section{Acknowledgments}

We thank Kirsten Bohn, Kate Bowman, Christina Bradley, Joe Collelo, Adrienne Crowly, Christine Fischer, Jacqueline Harvey, Jeff Horsley, Cary and Kari Myler, Mark Overfield (deceased), Scott Relyea, Todd Royer, Kelly Sant (deceased), Jesse Schomberg, Eric Snyder, Michele Thornton, and Jeff Varricchione for their help and diligence with the field and laboratory work.

Grant DEB-9306365 from the National Science Foundation and grant S97-07 from the Idaho State University Graduate Research and Scholarship Committee funded this research.
}

events interspersed with periods of residence and processing on the streambed (Newbold et al. 1982; Cushing et al. 1993). This description of FPOM movement highlights the two vectors through which FPOM influences the flow of energy and materials within streams: a vertical vector acting to couple the water column with the stream bed and a longitudinal vector that links upstream to downstream reaches. Identifying the specific mechanisms responsible for FPOM deposition and transport and evaluating the relative importance of each is currently an unexplored area of stream ecology.

Progress in the study of FPOM dynamics within streams has been limited by difficulty associated with identifying specific particles and their sources. In-stream processing of FPOM obscures particle origins by creating and amalgamating particles from a variety of allochthonous and autochthonous sources. As a result, much of our understanding of particulate movement in flowing waters is based upon theoretical models of turbulent transport (Dobbins 1944; Yalin 
Table 1. Dates and conditions during the field releases of ${ }^{14} \mathrm{C}$-labeled POM. FPOM, fine particulate organic matter, 53-106 $\mu \mathrm{m}$; VFPOM, very fine particulate organic matter, 15-52 $\mu \mathrm{m}$; MPOM, medium particulate organic matter, 107-250 $\mu \mathrm{m}$; diatoms, Asterionella $>52 \mu \mathrm{m}$; DOC, sucrose.

\begin{tabular}{|c|c|c|c|c|c|}
\hline Location & Notation & Date & Flow condition & $\begin{array}{l}\text { Discharge } \\
\left(\mathrm{m}^{3} \mathrm{~s}^{-1}\right)\end{array}$ & Particle types \\
\hline \multirow[t]{2}{*}{ Upper Bloomington Creek } & UBCL-96 & Aug 1996 & Base flow & 0.004 & FPOM, VFPOM \\
\hline & $\mathrm{UBCH}$ & Jun 1997 & Spring runoff & 0.077 & FPOM, VFPOM, MPOM \\
\hline Middle Bloomington Creek & $\mathrm{MBC}$ & Aug 1996 & Base flow & 0.225 & FPOM, VFPOM \\
\hline Lower Bloomington Creek & LBC & Aug 1995 & Base flow & 0.300 & FPOM \\
\hline Deep Creek & $\mathrm{DCH}$ & Apr 1996 & Base flow & 0.897 & FPOM, VFPOM \\
\hline
\end{tabular}

1977; Smith 1982; Denny and Shibata 1989; McNair et al. 1997), observations of particle behavior within laminar flow (O’Melia 1980), and flume experiments (Eckman 1990; Reynolds et al. 1990). Novel methods of labeling natural particles (Wolfinbarger and Crosby 1983; Cushing et al. 1993; Hall et al. 1996) and the development of seston analogs (Miller and Georgian 1992) have recently allowed stream ecologists to quantify FPOM transport and deposition in natural streams. Application of these methods promises to stimulate the study of particulate material as similar methods continue to advance our understanding of solute dynamics in lotic environments (Newbold et al. 1981; Bencala and Walters 1983; Stream Solute Workshop 1990).

Of the studies that have been conducted using natural or analog particles, most have focused on quantifying particle transport distances in streams. Particle transport distance $\left(S_{\mathrm{P}}\right)$ represents the mean longitudinal distance traveled by a particle between its introduction, or entrainment, into the water column and its point of deposition. Whereas $S_{\mathrm{P}}$ describes the movement of FPOM in the longitudinal dimension, a related parameter, the deposition velocity $\left(v_{\text {dep }}\right)$ quantifies the vertical movement of FPOM. The deposition velocity is obtained from the transport distance by $v_{\text {dep }}=u h / S_{\mathrm{P}}$, where $u$ and $h$ are mean water velocity and depth, respectively (Newbold et al. 1991). Thus, $v_{\text {dep }}$ removes the scaling effect of depth and velocity on transport distance and, in principle, provides a more effective parameter for assessing which channel and/ or benthic attributes influence the flux of suspended material to the streambed.

Much of the literature regarding particle deposition in running water has focused on the role of gravitational settling. Theoretical approaches often view particle dynamics in the water column as a balance between downward gravitational settling, governed by Stokes fall velocity, and upward dispersion by turbulent transport. These approaches suggest that the deposition velocity of particles should be, to a first approximation, equivalent to the fall velocity $\left(v_{\text {fall }}\right)$ (Dobbins 1944; Cordoba-Molina et al. 1978; Smith 1982; Reynolds et al. 1990), or at least strongly influenced by fall velocity (Einstein and Krone 1962; Eckman 1990). In fact, results from several experiments have supported equivalence between deposition and fall velocity, at least under some conditions (Einstein and Krone 1962; Reynolds et al. 1990; Miller and Georgian 1992). Cushing et al. (1993) found that FPOM particles $(50-100 \mu \mathrm{m})$ in two Idaho streams deposited at a rate considerably less than $v_{\text {fall }}$ and speculated (following Einstein and Krone 1962) that this might have been the result of greater-than-critical bed shear. However, Minshall et al. (2000) failed to find an association between $v_{\text {dep }}$ and bed roughness (as Manning's $n$ ) or channel shear stress using releases of a single size class of organic particles across a gradient of physical conditions.

An obvious approach to addressing the question of whether gravitational effects are important is to compare deposition velocities of particles with differing fall velocities. Hall et al. (1996) found that bacterial cells deposited at a rate far greater than their $v_{\text {fall }}$ and that this rate was similar to the range of deposition velocities observed by Cushing et al. (1993) for much larger FPOM. Interestingly, Miller and Georgian (1992) and Webster et al. 1999 reported similar values of $v_{\text {dep }}$ for corn pollen, as did Reynolds et al. (1990) for Lycopodium spores. Together, these results call into question whether fall velocity plays any significant role in determining field deposition rates, at least for fine particles with low fall velocity. As fall velocity increases, its importance is also likely to increase, raising the question of where along the spectrum of fall velocities this transition occurs.

As a means of assessing the relationship between particle size and deposition, we conducted field experiments using ${ }^{14} \mathrm{C}$-labeled natural particles in streams representing a gradient of physical conditions. Our specific objectives were to (1) quantitatively compare the deposition velocity of various organic particle sizes and types, (2) assess of the relationship between $v_{\text {dep }}$ and $v_{\text {fall }}$ as a means of determining where along the particle size continuum fall velocity becomes important, (3) examine the relationship between specific physical features of streams and organic particle deposition and transport, and (4) discuss the mechanisms responsible for fine particle deposition in light of the current results.

\section{Study sites}

This research was conducted in two streams located in southeastern Idaho (Table 1). In Bloomington Creek (BC), experiments were conducted in both a first- and second-order segment. In the first-order site (Upper Bloomington Creek, UBC), experiments occurred during two distinct, hydrological stages: spring snowmelt and summer base flow (UBCH and UBCL, respectively; Table 1). In the second-order Bloo- 
mington Creek location (Middle Bloomington Creek, MBC), research was conducted only during base flow (see Minshall et al. 2000 for a detailed description of all Bloomington Creek sites).

Our other experimental location was Deep Creek (DC). Deep Creek arises from a series of large springs $(Q \sim 1,000$ $\mathrm{L} \mathrm{s}^{-1}, \mathrm{DCH}$ ) that produce a stable hydrograph in the experimental segment except during periods of agricultural diversion. At these times, discharge is reduced by $\sim 98 \%$ (DCL). Experiments in Deep Creek were conducted under each flow condition. In all, FPOM and very fine particulate organic matter (VFPOM, 15-52 $\mu \mathrm{m}$ ) experiments were conducted under five distinct hydrological conditions (Table 1).

\section{Methods}

Particle labeling-Seston was collected from each study site by passing stream flow through nested Nitex ${ }^{\sqrt{T W}}$ mesh nets $(1,000,52$, and $15 \mu \mathrm{m})$. Collected detritus was chilled, but not frozen, to minimize microbial and physical effects on particle size, and transferred to the laboratory. In the laboratory, particles collected in the $53-\mu \mathrm{m}$ net were wet-sieved through 106- and 53- $\mu \mathrm{m}$ standard sieves. Collected FPOM and VFPOM (53-106 and 16-52 $\mu \mathrm{m})$ were centrifuged at $5,000 \mathrm{rpm}$, the supernatant was decanted, and the volume and wet weight (WW) of the pellet were determined.

Approximately $15 \mathrm{ml}$ of $0.01 \mathrm{~N} \mathrm{NaOH}$ was added, and the FPOM was resuspended using a vortex mixer, centrifuged, and decanted. Using $0.01 \mathrm{~N} \mathrm{NaOH},{ }^{14} \mathrm{C}$ dimethyl sulfoxide was washed from its ampoule into the tube containing the pelleted material. The pellet was mixed with a glass rod for $2 \mathrm{~min}$, and the methylation reaction was allowed to proceed at room temperature for $40 \mathrm{~min}$ (Wolfinbarger and Crosby 1983). Approximately $10 \mathrm{ml}$ of reverse osmosis water was added in order to stop the reaction. After several rinses of the pellet, subsamples were placed into scintillation vials containing $15 \mathrm{ml}$ of liquid scintillation cocktail for determination of ${ }^{14} \mathrm{C}$ concentration of FPOM using a liquid scintillation analyzer as described below. Medium particulate organic matter (MPOM, 107-250 $\mu \mathrm{m}$ ) was labeled using identical methods. Live diatoms (Asterionella sp.) were labeled by incubation in a growth medium that included ${ }^{14} \mathrm{C}$ sodium bicarbonate.

Field releases-At Upper Bloomington Creek, we conducted paired, but separate, experiments using FPOM and VFPOM during base flow in 1996 and 1997 (UBCL-96 and UBCL-97) and during spring snowmelt in 1997 (UBCH) (Table 1). A third particle size class (MPOM) and Asterionella sp. also were released in Upper Bloomington Creek in 1997 (Table 1). At Middle Bloomington Creek, a single paired experiment (FPOM and VFPOM) was conducted in 1996. We conducted experiments with FPOM and VFPOM at Deep Creek under normal flow conditions (DCH) in 1996 and 1997. We also conducted two experiments at reduced discharge (DCL, irrigation diversion) in 1997 (Table 1). At each location, ${ }^{14} \mathrm{C}$-labeled particle additions were conducted in the same stream reach, except at DCL, where VFPOM and FPOM were released into separate, but geomorphically similar, reaches.
For each experiment, ${ }^{14} \mathrm{C}$-labeled particles and rhodamineWT were metered into study reaches over various time intervals (9-28 min). Delivery of the rhodamine-WT solution and associated particle suspension was accomplished using a variable speed peristaltic pump. Each particle size class was released to the stream individually. Releases at a single location were separated by $2-24 \mathrm{~h}$ to permit adequate time for clearance of particles from the water column. Sampling transects were established at various distances downstream from the release site, with smaller intervals near the release site and larger intervals downstream. Samples $(910 \mathrm{ml})$ were collected from middepth in the thalweg using uniform widemouth containers at timed intervals, determined from preliminary trials using dye or $\mathrm{Cl}^{-}$. Collection time was $<5 \mathrm{~s}$. Smaller $(227 \mathrm{ml})$ samples were collected at UBC and DC under low flow because of shallow thalweg depths. A 15-ml subsample was removed from each container for determination of rhodamine-WT concentration, and the remaining water was filtered through a $5-\mu \mathrm{m}$ cellulose nitrate filter. Filters were placed into scintillation vials in the field and returned to Idaho State University. Filters were covered with liquid scintillation cocktail in the laboratory and radio assayed using a Wallac model 1415 or a Packard Tri-Carb 2100TR liquid scintillation analyzer.

Downstream loss of rhodamine-WT was used to calculate dilution within the sampling reach. Coincident releases of rhodamine-WT and chloride or bromide (as $\mathrm{NaCl}$ or $\mathrm{NaBr}$, respectively) in 1995 and 1996 determined rhodamine-WT to be a suitable conservative tracer for these experiments, so we did not use cotracers in 1997. Rhodamine-WT was measured using a Hitachi F-2000 in 1995-1996, and a PerkinElmer LS50B luminescence spectrometer in 1997. Chloride and bromide were measured using an Alpchem autoanalyzer.

During an experimental release of ${ }^{14} \mathrm{C}$-labeled POM, the amount of labeled POM remaining in transport at each station can be calculated using by

$$
F_{(x)}=\sum C_{(x)} Q t_{\mathrm{S}},
$$

where $F_{(x)}$ is the load of particles passing a specific transect (disintegrations per minute, $\mathrm{dpm}), C_{(x)}$ is the particle concentration (dpm L $\left.{ }^{-1}\right)$, and $t_{\mathrm{S}}$ is the time between samples (s). The longitudinal loss rate of particles $\left(k_{\mathrm{P}}, \mathrm{m}^{-1}\right)$ was determined using $F_{(x)}=F_{(0)} \exp \left(-k_{\mathrm{P}} x\right)$ (Newbold et al. 1981, $1991)$, where $F_{(0)}$ represents the amount of particles injected $(\mathrm{dpm})$ and $x$ is the longitudinal distance $(\mathrm{m}) . k_{\mathrm{P}}$ estimates were determined by nonlinear regression. As noted previously, the inverse of $k_{\mathrm{P}}$ is equal to the mean transport distance $\left(S_{\mathrm{P}}\right)$ of the respective material. Multiplying $k_{\mathrm{P}}$ by the width-specific discharge $\left(Q_{\mathrm{W}}\right.$; equal to the product of mean water velocity and depth) determines the field deposition velocity $\left(v_{\text {dep }}, \mathrm{m} \mathrm{s}^{-1}\right)$.

Particle fall velocity $\left(v_{\text {fall }}\right)$ was calculated using Stokes Law. Mean diameter was measured for 100 particles using a light microscope $(\times 400$ magnification). Percent organic matter was determined by combustion. Organic and inorganic matter densities were assumed to equal 1.25 and 2.50 $\mathrm{g} \mathrm{cm}^{-3}$, respectively (Webster et al. 1988). Particle density was calculated as described by Minshall et al. (2000). 


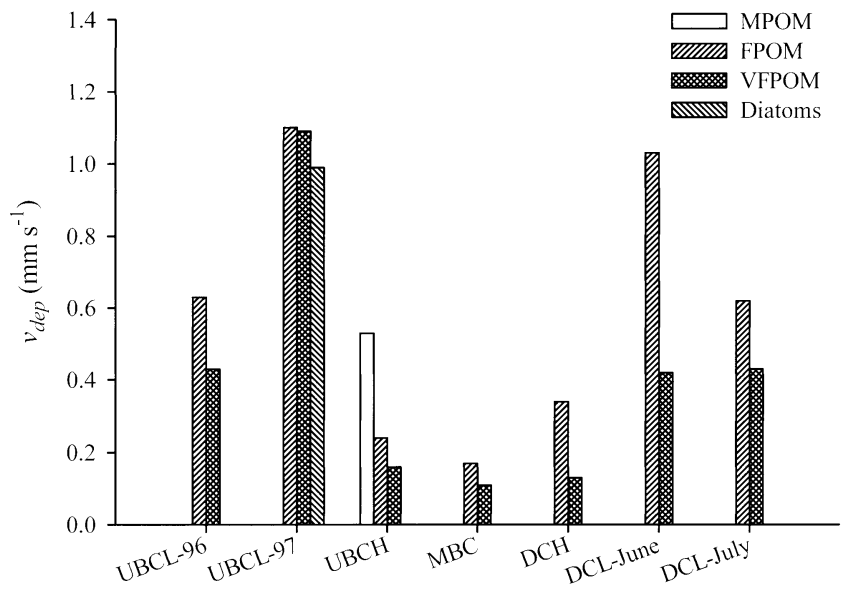

Fig. 1. A comparison of deposition velocity $\left(v_{\text {dep }}\right)$ at individual research locations for very fine (VFPOM), fine (FPOM), and medium particulate organic matter (MPOM) and the diatom Asterionella sp. FPOM data from Minshall et al. (2000).

Stream hydrology — A variety of hydrological and benthic characteristics were measured in order to assess the relationship between specific stream attributes and POM transport and deposition. Mean water velocity $\left(u, \mathrm{~m} \mathrm{~s}^{-1}\right)$ and discharge $\left(Q, \mathrm{~m}^{3} \mathrm{~s}^{-1}\right)$ were determined using conservative tracer additions (Triska et al. 1989; Stream Solute Workshop 1990). Stream width $(w, \mathrm{~m})$ was calculated as the average of 30 100 measurements. Mean water depth $(h, \mathrm{~m})$ was calculated as $h=Q /(u w)$. Water surface slope was assessed for each stream segment using a leveling laser (Topcon RL-H), a stadia rod, and a tape measure. Derived hydrological variables (e.g., shear stress, Reynolds number, Manning's $n$ ) were calculated as described by Minshall et al. (2000).

Transient storage was determined using a modified onedimensional advection-dispersion model (Bencala and Walters 1983). Optimum fit of the field and model data was accomplished using an automated least squares technique (Hart 1995) and visual inspection. Best fit versions of the transient storage equations produced estimates of cross-sectional area of the storage zone $\left(A_{\mathrm{s}}, \mathrm{m}^{2}\right)$, and the coefficient of exchange between the free-flowing and storage zones $(\alpha$, s). Additional characteristics of the transient storage zone (e.g., relative extent of the storage zone $\left[A_{\mathrm{S}} / A\right]$, uptake length of water $\left[S_{\mathrm{w}}, \mathrm{m}\right]$ ) were derived using published equations (Morrice et al. 1997). A mass transfer coefficient $\left(v_{\mathrm{w}}, \mathrm{m} \mathrm{s}^{-1}\right)$ was calculated by multiplying $\alpha$ by $h$ in order to express water parcel movement from the channel to transient storage habitats in units of distance per unit time (e.g., the mathematical equivalent of $v_{\mathrm{dep}}$ ). An experimental Damkohler number (DaI) was used to select reach lengths that minimized uncertainty associated with parameter estimates (Harvey and Wagner 2000). Our storage values were based on reach lengths that produced $\mathrm{DaI}$ values closest to 1 (minimum uncertainty in parameter estimation). Modeled reach lengths ranged from 33 to $500 \mathrm{~m}$.

Statistical analysis-An $F$-ratio produced using the extra sum of squares principle (Draper and Smith 1996) was used to determine if significant differences existed between estimates of $k_{\mathrm{P}}$ (slope) within specific experiments. At UBCH and UBCL-97, this method was used to test for overall differences, as well as paired comparisons (e.g., VFPOM vs. FPOM, VFPOM vs. MPOM, etc.). A paired Student's $t$-test was used to test for differences between FPOM and VFPOM $v_{\text {dep }}$ and between estimates of $v_{\text {dep }}$ and $v_{\text {fall }}$. Relationships between specific physical characteristics of the experimental locations and FPOM and VFPOM $S_{\mathrm{P}}$ and $v_{\text {dep }}$ estimates were explored using regression analysis.

\section{Results}

Particle size and $\mathrm{v}_{\text {dep }}$-Deposition velocity varied from 0.06 to $1.10 \mathrm{~mm} \mathrm{~s}^{-1}$ across particle types and locations. Without exception, larger detritus particles deposited more rapidly than smaller size classes (Fig. 1; Tables 2, 3). For example, $v_{\text {dep }}$ increased from $0.16 \mathrm{~mm} \mathrm{~s}^{-1}$ for VFPOM to $0.24 \mathrm{~mm} \mathrm{~s}^{-1}$ for FPOM to $0.54 \mathrm{~mm} \mathrm{~s}^{-1}$ for MPOM at UBCH (Table 2). The mean difference in $v_{\text {dep }}$ between VFPOM and FPOM (particle size classes for which we have multiple releases) was $0.19 \mathrm{~mm} \mathrm{~s}^{-1}$ and ranged from $0.61 \mathrm{~mm} \mathrm{~s}^{-1}$ at Deep Creek under low flow conditions to $0.01 \mathrm{~mm} \mathrm{~s}^{-1}$ at UBCL-97. A paired Student's $t$-test confirmed that deposition velocity of FPOM was greater than VFPOM when all experiments were analyzed $(P=0.049)$. However, deposition velocity varied more across sites than between size clas-

Table 2. FPOM transport characteristics from ${ }^{14} \mathrm{C}$-POM additions to Upper Bloomington Creek, 1997. Abbreviations: $k_{\mathrm{P}}$, longitudinal loss rate; $S_{\mathrm{P}}$, transport distance; $\nu_{\text {dep }}$, deposition velocity; $\nu_{\text {fall }}$, fall velocity; UBC, Upper Bloomington Creek; FPOM, fine particulate organic matter (53-106 $\mu \mathrm{m})$; VFPOM, very fine particulate organic matter $(15-52 \mu \mathrm{m})$. MPOM, medium particulate organic matter (107-250 $\mu \mathrm{m})$; diatoms, Asterionella. FPOM data from Minshall et al. (2000).

\begin{tabular}{lccccccc}
\hline \hline & \multicolumn{3}{c}{ UBCL-97 } & & \multicolumn{3}{c}{ UBCL } \\
\cline { 2 - 3 } & FPOM & VFPOM & Diatoms & & MPOM & FPOM & VFPOM \\
\hline Size class $(\mu \mathrm{m})$ & $54-106$ & $15-53$ & $>15$ & & $107-250$ & $54-106$ & $15-53$ \\
$k_{\mathrm{P}}\left(\mathrm{m}^{-1}\right)$ & 0.232 & 0.232 & 0.205 & & 0.0106 & 0.0042 & 0.0032 \\
$S_{\mathrm{P}}(\mathrm{m})$ & 4.3 & 4.4 & 4.8 & & 94.4 & 238 & 308 \\
$\nu_{\text {dep }}\left(\mathrm{mm} \mathrm{s}^{-1}\right)$ & 1.10 & 1.09 & 0.99 & & 0.53 & 0.24 & 0.16 \\
$\nu_{\text {fall }}\left(\mathrm{mm} \mathrm{s}^{-1}\right)$ & 1.55 & 0.11 & $0.17 *$ & & 4.49 & 0.98 & 0.09 \\
$\nu_{\text {dep }} / \nu_{\text {fall }}$ & 0.71 & 9.90 & 5.82 & & 0.19 & 0.24 & 1.78 \\
\hline
\end{tabular}

* From Wetzal 1983. 
Table 3. Fine particulate organic matter (FPOM) and very fine particulate organic matter (VFPOM) transport variables determined from seven paired particle additions. $k_{\mathrm{P}}$, longitudinal loss rate; $S_{\mathrm{P}}$, transport distance; $\nu_{\text {dep }}$, deposition velocity; $\nu_{\text {fall }}$, fall velocity; UBC, Upper Bloomington Creek; MBC, Middle Bloomington Creek; DC, Deep Creek; H, high flow; L, low flow. FPOM data from Minshall et al. (2000).

\begin{tabular}{|c|c|c|c|c|c|c|c|c|c|c|c|c|c|c|}
\hline & \multicolumn{2}{|c|}{ UBCL-96 } & \multicolumn{2}{|c|}{ UBCL-97 } & \multicolumn{2}{|c|}{$\mathrm{UBCH}$} & \multicolumn{2}{|c|}{ MBC } & \multicolumn{2}{|c|}{$\mathrm{DCH}$} & \multicolumn{2}{|c|}{ DCL-June } & \multicolumn{2}{|c|}{ DCL-July } \\
\hline$k_{\mathrm{P}}\left(\mathrm{m}^{-1}\right)$ & 0.1109 & 0.0476 & 0.2320 & 0.2273 & 0.0042 & 0.0032 & 0.0019 & 0.0012 & 0.0046 & 0.0009 & 0.1140 & 0.0429 & 0.1020 & 0.0658 \\
\hline$\nu_{\text {dep }}\left(\mathrm{mm} \mathrm{s}^{-1}\right)$ & 0.63 & 0.43 & 1.10 & 1.09 & 0.24 & 0.16 & 0.17 & 0.11 & 0.34 & 0.13 & 1.03 & 0.42 & 0.62 & 0.43 \\
\hline$\nu_{\text {fall }}\left(\mathrm{mm} \mathrm{s}^{-1}\right)$ & 1.55 & 0.11 & 1.55 & 0.11 & 0.98 & 0.09 & 1.47 & 0.09 & 2.26 & 0.17 & 2.08 & 0.15 & 2.08 & 0.15 \\
\hline$\nu_{\text {fall }} / \nu \%$ dep & 0.41 & 3.90 & 0.71 & 9.91 & 0.24 & 1.78 & 0.12 & 1.22 & 0.15 & 0.76 & 0.50 & 2.8 & 0.30 & 2.87 \\
\hline
\end{tabular}

ses (Table 3; Fig. 1). For example, variation in VFPOM $v_{\text {dep }}$ ranged from 0.11 to $1.09 \mathrm{~mm} \mathrm{~s}^{-1}\left(\delta v_{\text {dep }}=0.98 \mathrm{~mm} \mathrm{~s}^{-1}\right)$. Variation in $v_{\text {dep }}$ of FPOM and VFPOM among sites was positively correlated $(r=0.85, P=0.02)$.

$\mathrm{v}_{\text {dep }}$ versus $\mathrm{v}_{\text {fall }}$-The measured $v_{\text {dep }}$ of FPOM was less than the respective FPOM $v_{\text {fall }}$ for each of the seven experiments, with an average ratio of $v_{\text {dep }}: v_{\text {fall }}$ of 0.35 (significantly less than $1, P<0.01$; Table 3 ). By contrast, the ratio of $v_{\text {dep }}: v_{\text {fall }}$ for VFPOM averaged 3.3 (significantly greater than $1, P=$ 0.007; Table 3). For the single experiment involving MPOM, the $v_{\text {dep }}: v_{\text {fall }}$ ratio was 0.12 (Table 2). Asterionella sp. deposited at approximately the same rate as particulate detritus, with a $v_{\text {dep }} 5.8$ times greater than its predicted $v_{\text {fall }}(0.17 \mathrm{~mm}$ $\mathrm{s}^{-1}$; Wetzel 1983; Table 2). Thus, among particle types, $v_{\text {dep }}$ : $v_{\text {fall }}$ decreased with increasing particle size and $v_{\text {fall }}$, and there was far less variation in $v_{\text {dep }}$ between size classes than predicted by variation in $v_{\text {fall }}$. Within size classes there was not a significant correlation between $v_{\text {dep }}$ and $v_{\text {fall }}(r=0.44$ and 0.05 and $P=0.27$ and 0.99 for FPOM and VFPOM, respectively; Fig. 2).

Physical controls of deposition velocity-Channel slope, reach-average shear stress $(\tau)$, and benthic roughness (as Manning's $n$ ) were poorly associated with FPOM and VFPOM $v_{\text {dep }}$ (Table 4). In fact, the maximum values of FPOM $v_{\text {dep }}$ occurred under conditions of minimum and maximum channel slope and bed roughness (Fig. 3). Mean water

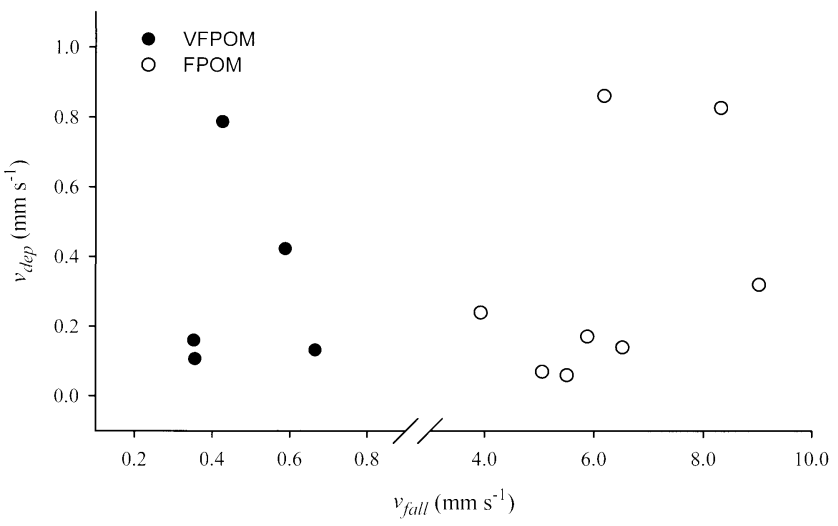

Fig. 2. Comparing $v_{\text {fall }}$ and $v_{\text {dep }}$ for very fine (VFPOM; solid circles) and fine particulate organic matter (FPOM; open circles). FPOM data are from Minshall et al. (2000). depth $(h)$, mean water velocity $(u)$, and their product $\left(Q_{\mathrm{w}}\right)$ were negatively related to FPOM and VFPOM deposition, although none of these relationships were significant (Table 4; Fig. 3). Among the results from streams with flows exceeding $15 \mathrm{~L} \mathrm{~s}^{-1}$, VFPOM $v_{\text {dep }}$ varied little $(0.11-0.16 \mathrm{~mm}$ $\left.\mathrm{s}^{-1}\right)$, despite a wide range in flow (77-897 $\mathrm{L} \mathrm{s}^{-1}$ ) and other physical characteristics. FPOM $v_{\text {dep }}$ similarly showed little variation among the larger streams, as we previously noted (Minshall et al. 2000). For both VFPOM and FPOM, the highest deposition velocities occurred in the streams with the lowest values of depth and velocity (UBCL and DCL; Tables $2,4)$. We also observed a significant, negative relationship between FPOM $v_{\text {dep }}$ and hydraulic radius $(R=A /(2 h+w)$; $r=-0.64, P=0.05)$ and a similar, but insignificant, relationship between VFPOM $v_{\text {dep }}$ and $R(r=-0.71, P=$ 0.07 ) (Fig. 3). Both particle size classes had the highest deposition velocities in streams with the largest values of $A_{\mathrm{S}} /$ $A$, although neither relationship was significant. When data were combined across particle sizes, a significant association was detected between $v_{\text {dep }}$ and $A_{\mathrm{S}} / A\left(v_{\text {dep }}=-0.149+\right.$ $\left.\left(4.583 \cdot A_{\mathrm{s}} / A\right), r^{2}=0.48, P=0.005\right)$. As a means of representing particle size in this analysis, $v_{\text {fall }}$ and $A_{\mathrm{S}} / A$ were combined in a multiple regression analysis. Using a forward stepwise procedure, we determined that including $v_{\text {fall }}$ did not significantly add to the ability of the regression model to predict $v_{\text {dep }}$. For both size classes, $v_{\text {dep }}$ was unrelated to the mass transfer coefficient of water, $v_{\mathrm{w}}$.

Particle transport distances-POM transport distance varied considerably (Tables 2, 3), ranging from a maximum of $1,153 \mathrm{~m}$ for VFPOM in DCH to $4.3 \mathrm{~m}$ for FPOM in UBCL97. Because transport distance is determined directly from the regression of individual releases, we are able to test for significant differences between particle types within individual sites (Table 5). Transport distance of our largest detrital size class (MPOM) traveled a shorter distance than both FPOM and VFPOM at Upper Bloomington Creek during high flow (UBCH) (Table 2). However, comparison of slopes detected a significant difference between VFPOM and MPOM, only (Table 5). The diatom Asterionella sp. had a mean travel distance similar to those of VFPOM and FPOM in UBC under low-flow conditions (Tables 2, 5). Significant differences between VFPOM and FPOM were detected in $\mathrm{DC}$ and $\mathrm{MBC}$ experiments but were not observed in UBC under both high- and low-flow conditions (Table 5). Like 
Table 4. Hydrological and transient storage parameters determined for the six locations used in the fine particulate organic matter (FPOM) and very fine POM (VFPOM) experiments and results of the Pearson correlation analysis relating each variable to mean transport distance $\left(S_{\mathrm{P}}\right)$ and deposition velocity $\left(\nu_{\text {dep }}\right)$. FPOM and VFPOM were conducted in separate reaches. FPOM statistics also include data from Lower Bloomington Creek, Smiley Creek, and the Salmon River (Cushing et al. 1993; Minshall et al. 2001). Abbreviations: $h$, water depth; $u$, water velocity; $A$, cross-sectional area; $Q$, discharge; $Q_{\mathrm{w}}$, unit width discharge; $S$, channel slope; $U_{*}$, shear velocity; $\tau$, shear stress; $\alpha$, transient storage coefficient of exchange; $A_{\mathrm{s}}$, cross-sectional area of the transient storage zone; $\nu_{\mathrm{w}}$, mass transfer coefficient of water; $S_{\mathrm{w}}$, uptake length of water; UBC, Upper Bloomington Creek; MBC, Middle Bloomington Creek, LBC, Lower Bloomington Creek; DC, Deep Creek; H, high flow; L, low flow. FPOM data from Minshall et al. (2000).

\begin{tabular}{|c|c|c|c|c|c|c|c|c|c|c|c|c|c|c|}
\hline & UBCL & $\mathrm{UBCH}$ & $\mathrm{MBC}$ & $\mathrm{DCH}$ & $\begin{array}{c}\text { DCL } \\
\text { FPOM }\end{array}$ & $\begin{array}{c}\text { DCL } \\
\text { VPOM }\end{array}$ & \multicolumn{2}{|c|}{ FPOM $S_{\mathrm{P}}$} & \multicolumn{2}{|c|}{ FPOM $\nu_{\text {dep }}$} & \multicolumn{2}{|c|}{ VFPOM $S_{\mathrm{P}}$} & \multicolumn{2}{|c|}{ VFPOM $\nu_{\text {dep }}$} \\
\hline$h(\mathrm{~m})$ & 0.09 & 0.26 & 0.31 & 0.33 & 0.06 & 0.06 & 0.54 & 0.17 & -0.70 & 0.05 & 0.91 & 0.03 & -0.86 & 0.06 \\
\hline$Q_{\mathrm{W}}\left(\mathrm{m}^{2} \mathrm{~s}^{-1}\right)$ & 0.006 & 0.057 & 0.090 & 0.162 & 0.008 & 0.008 & 0.41 & 0.31 & -0.53 & 0.17 & 0.98 & $<0.01$ & -0.76 & 0.14 \\
\hline$Q\left(\mathrm{~m}^{3} \mathrm{~s}^{-1}\right)$ & 0.004 & 0.077 & 0.225 & 0.897 & 0.013 & 0.013 & 0.47 & 0.24 & -0.46 & 0.26 & 0.88 & 0.05 & -0.54 & 0.35 \\
\hline$\widetilde{A}\left(\mathrm{~m}^{2}\right)$ & 0.06 & 0.40 & 0.74 & 1.78 & 0.12 & 0.11 & 0.63 & 0.09 & -0.58 & 0.13 & 0.95 & 0.01 & -0.64 & 0.25 \\
\hline$\tau\left(\right.$ dyne $\left.\mathrm{cm}^{-2}\right)$ & 1,236 & 3,571 & 547 & 248 & 55 & 47 & -0.18 & 0.67 & -0.12 & 0.78 & 0.26 & 0.68 & -0.11 & 0.86 \\
\hline Manning's $n$ & 0.92 & 0.56 & 0.18 & 0.08 & 0.11 & 0.10 & -0.44 & 0.27 & 0.35 & 0.40 & -0.57 & 0.31 & 0.68 & 0.21 \\
\hline$\alpha\left(\min ^{-1}\right)$ & 0.050 & 0.040 & 0.006 & 0.008 & 0.058 & 0.069 & -0.75 & 0.03 & 0.68 & 0.06 & 0.94 & 0.02 & 0.68 & 0.21 \\
\hline$A_{\mathrm{S}}\left(\mathrm{m}^{2}\right)$ & 0.009 & 0.040 & 0.078 & 0.089 & 0.022 & 0.029 & 0.89 & $<0.01$ & -0.79 & 0.02 & 0.97 & 0.01 & -0.85 & 0.07 \\
\hline$A_{\mathrm{S}} / A$ & 0.150 & 0.100 & 0.105 & 0.050 & 0.184 & 0.262 & -0.70 & 0.05 & 0.83 & 0.01 & -0.78 & 0.12 & 0.54 & 0.34 \\
\hline$\nu_{\mathrm{w}}\left(\mathrm{mm} \mathrm{s}^{-1}\right)$ & 0.071 & 0.173 & 0.030 & 0.044 & 0.054 & 0.070 & -0.43 & 0.29 & 0.02 & 0.96 & -0.43 & 0.47 & -0.04 & 0.95 \\
\hline
\end{tabular}

$v_{\text {dep }}$, variation in FPOM and VFPOM $S_{\mathrm{P}}$ were significantly associated among streams $(P=0.03)$.

Minshall et al. (2000) identified positive associations between FPOM transport distance and specific measures of stream size and hyporheic extent. VFPOM $S_{\mathrm{P}}$ was positively associated with water velocity $(u)$, width-specific discharge $\left(Q_{\mathrm{W}}\right)$, discharge $(Q)$, and stream cross-sectional area $(A)$ (Ta-
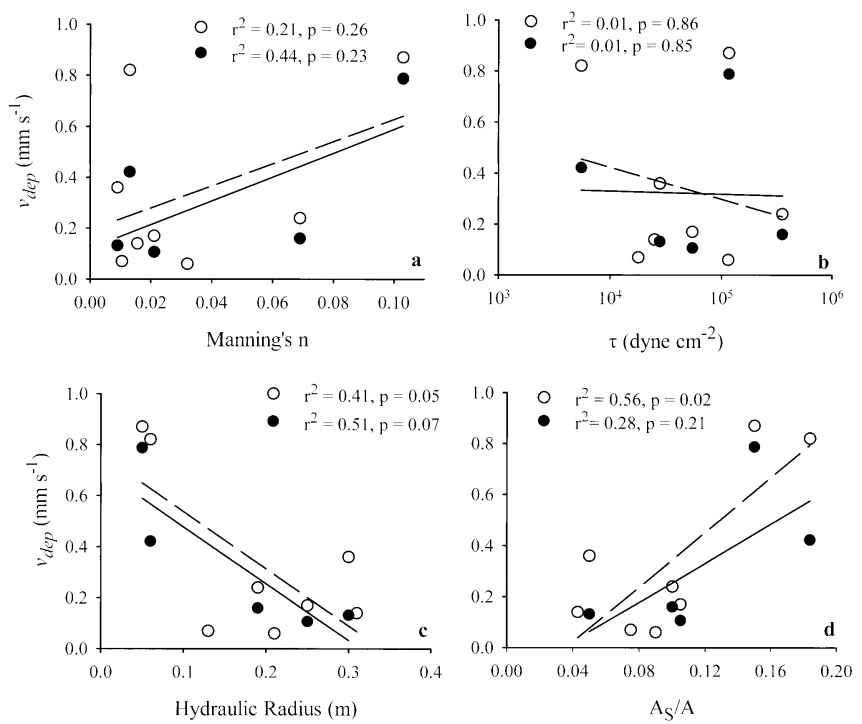

Fig. 3. Relationships between very fine (VFPOM; solid circles, solid lines) and fine particulate organic matter (FPOM; open circles, dashed lines) deposition velocity $\left(v_{\text {dep }}\right)$ (a) Manning's $n$, (b) shear stress $(\tau)$, and (c) relative extent of the transient storage zone $\left(A_{\mathrm{S}} /\right.$ $A$, where $A_{\mathrm{S}}$ is the cross-sectional area of the storage zone and $A$ is the channel cross-sectional area). FPOM data is from Minshall et al. (2000). ble 4). FPOM $S_{\mathrm{P}}$ was also associated with $u, Q_{\mathrm{w}}$, and $A$ but was poorly related to $Q$ (Table 4 ). Both FPOM and VFPOM transport distance were positively correlated with the crosssectional area of the storage zone $\left(A_{\mathrm{S}} ; r^{2}=0.84\right.$ and 0.98 , respectively). FPOM and VFPOM $S_{\mathrm{P}}$ also were positively associated with the uptake length of water $\left(S_{\mathrm{w}} ; r^{2}=0.69\right.$ and 0.95 , respectively). However, the relationship between VFPOM $S_{\mathrm{P}}$ and $S_{\mathrm{W}}$ was slightly weaker than the association between width-specific discharge $\left(Q_{\mathrm{W}}\right)$ and VFPOM transport distance $\left(r^{2}=0.96\right)$. These results raise the question of whether the relationship between $S_{\mathrm{W}}$ and $S_{\mathrm{P}}$ is mechanistic

Table 5. Extra sum of squares comparisons of particle transport distance $\left(S_{\mathrm{P}}\right)$ for all experiments. Abbreviations: MBC, Middle Bloomington Creek; UBC, Upper Bloomington Creek; DC, Deep Creek; H, high flow; L, low flow; FPOM, fine particulate organic matter, 53-106 $\mu \mathrm{m}$; VFPOM, very fine particulate organic matter, 15-52 $\mu \mathrm{m}$; MPOM, medium particulate organic matter, 107-250 $\mu \mathrm{m}$; diatoms, Asterionella; DOC, sucrose. FPOM data from Minshall et al. (2000).

\begin{tabular}{llrc}
\hline \hline Location & \multicolumn{1}{c}{ Comparison } & $\begin{array}{c}F \\
\text { statistic }\end{array}$ & $\begin{array}{c}\text { Proba- } \\
\text { bility }\end{array}$ \\
\hline DCH & VFPOM vs. FPOM & 0.6 & $P>0.05$ \\
DCL & VFPOM vs. FPOM & 18.2 & $P<0.02$ \\
MBC & VFPOM vs. FPOM & 10.0 & $P<0.05$ \\
UBCL-96 & VFPOM vs. FPOM & 1.7 & $P>0.05$ \\
UBCH & VFPOM vs. FPOM vs. MPOM & 13.7 & $P<0.02$ \\
& VFPOM vs. FPOM & 3.3 & $P>0.05$ \\
& VFPOM vs. MPOM & 21.6 & $P<0.02$ \\
& FPOM vs. MPOM & 7.7 & $P>0.05$ \\
UBCL-97 & VFPOM vs. FPOM vs. Diatoms & 0.3 & $P>0.05$ \\
& VFPOM vs. FPOM & 0.0 & $P>0.05$ \\
& VFPOM vs. Diatoms & 0.2 & $P>0.05$ \\
& FPOM vs. Diatoms & 0.2 & $P>0.05$ \\
\hline
\end{tabular}


or an artifact of the relationship between $Q_{\mathrm{W}}$ and $S_{\mathrm{W}}(r=$ 0.93). In all cases, physical variables explained a greater amount of the variation in VFPOM $S_{\mathrm{P}}$ than in FPOM $S_{\mathrm{P}}$ (Table 4).

\section{Discussion}

$\mathrm{v}_{\text {dep }}, \mathrm{v}_{\text {fall }}$, and gravitational settling in streams-Traditional models of sediment deposition in streams have relied upon three basic elements presumed to govern sediment dynamics: gravitational settling, turbulent mixing, and near-bed shear stress. By quantifying $v_{\text {dep }}$ of different size classes in a group of physically distinct streams, we examined whether these same elements control the transport and deposition of fine organic particles in natural streams. $v_{\text {dep }}$ represents the hypothetical velocity at which particles move through the water column toward the sediments under field conditions. Specifically, comparing $v_{\text {dep }}$ to $v_{\text {fall }}$ among particle size classes and between differing streams serves to (1) evaluate the appropriateness of gravitational/hydrodynamic models in predicting fine organic particle transport under natural conditions and (2) examine the importance of nongravitational modes of deposition in streams.

One property of gravitational/hydrodynamic models is that they predict equivalency between field deposition velocity $\left(v_{\text {dep }}\right)$ and quiescent water fall velocity $\left(v_{\text {fall }}\right)$ in a simplified limiting case involving a well-mixed turbulent water column and particles settling through a laminar sublayer without resuspension (Dobbins 1944; Reynolds et al. 1990). The intensity and structure of turbulence in the water column, as influenced by roughness elements on the bed, is expected to modify this equivalence (Eckman 1990), as would shear stresses on the bed sufficient to prevent deposition (Einstein and Krone 1962). Nonetheless, the view that particle deposition is primarily a balance between upward turbulent mixing and gravitational settling suggests that fall velocity should have a large influence on observed deposition rates. It further suggests that physical characteristics of the stream, such as bed shear and bed roughness, also should influence observed deposition velocities. Our results showed a consistent influence of fall velocity on deposition velocity. However, the magnitude of this effect was small relative to the range in calculated fall velocities (Tables 2, 3, Fig. 2). $v_{\text {dep }}$ and $v_{\text {fall }}$ were poorly correlated within and between specific size classes (Fig. 2). Moreover, we found that shear stress and bed roughness (as Manning's $n$ ) were poorly associated with VFPOM and FPOM $v_{\text {dep }}$ (Fig. 3). Taken together, these results suggest that processes other than gravitational settling control the deposition of suspended fine organic particles but that gravity, while minimally influencing VFPOM, becomes increasingly important as particle diameter increases through the FPOM and MPOM size classes.

As a means of extending our results to larger and smaller particle size classes and to further assess the relationship between $v_{\text {dep }}$ and $v_{\text {fall }}$, we have combined our data with previously published values of particle diameter and $v_{\text {dep }}$ and overlain these data upon the theoretical relationship between particle diameter and $v_{\text {fall }}$ (Fig. 4). Our data suggest that the influence of particle size on seston deposition begins at

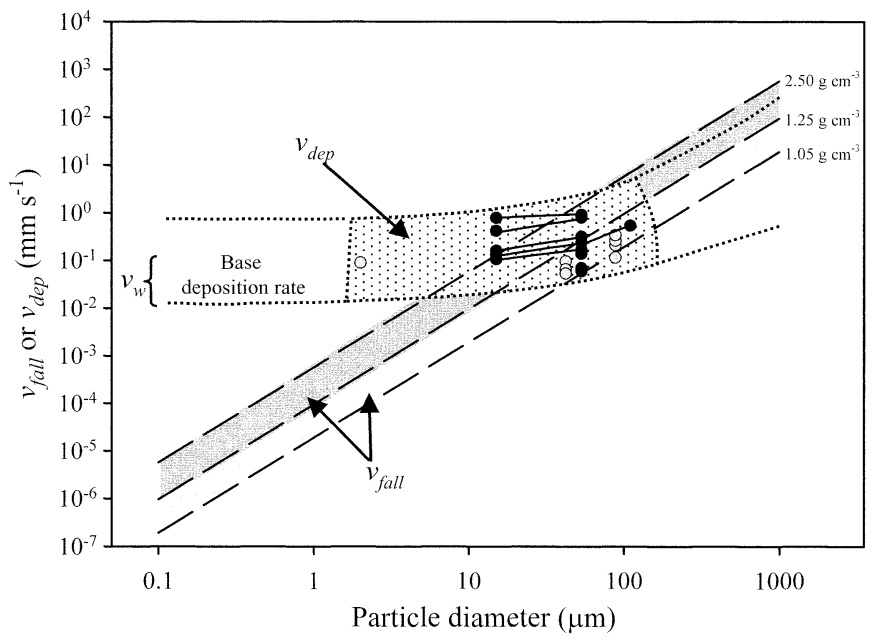

Fig. 4. The projected relationship between particle diameter, fall velocity, and deposition velocity in low-order streams under base flow. Fall velocities were calculated using Stokes law and particle densities equal to $1.05,1.25$, and $2.5 \mathrm{~g} \mathrm{~cm}^{-3}$. The two lower densities bracket the settling velocities of microbial cells (lightly shaded region), whereas the more darkly shaded region is intended to represent fall velocities more characteristic of detrital particles. The stippled area bounds existing data. The solid circles represent the current results, and the lines connecting specific circles link experiments at a single location (e.g., UBCL-97). The gray and open circles represent previously published data for bacteria (Hall et al. 1996) and corn pollen (Miller and Georgian 1992; Webster et al. 1999). Stippled lines represent the suggested trajectory of the $v_{\text {dep }}-$ particle diameter relationship. The lower limit of base deposition rate is established by the mass transfer coefficient of water $\left(v_{w}\right.$, bracket).

$\sim 50-100 \mu \mathrm{m}$. However, whether the rate at which $v_{\text {dep }}$ increases for larger particles $(>100 \mathrm{~mm})$ mimics $v_{\text {fall }}$ or whether the $v_{\text {dep }}$ changes less rapidly (stippled lines in Fig. 4) remains unclear. Figure 4 also indicates that $v_{\text {fall }}$ and $v_{\text {dep }}$ converge within the size range most studies have examined. The research by Hall et al. (1996) using fluorescently labeled bacteria is a notable exception. We also suggest that the mass transfer coefficient of water, $v_{\mathrm{w}}$, is likely to define the lower limit of particle deposition rates in streams. Figure 4 indicates that further research with smaller $(<10 \mu \mathrm{m})$ and larger $(>150 \mu \mathrm{m})$ particles is required to clarify whether the relationship between particle size and $v_{\text {dep }}$ is real or whether the data represent scatter around the predicted particle size$v_{\text {fall }}$ relationship (shaded areas of Fig. 4).

Further support for the hypothesis that gravitational forces become incipiently important through the size ranges used in this study comes from examining the predicted distribution of specific seston size classes within the water column. Early work by Rouse (1937) established that the vertical distribution of particles in flowing waters was determined by the ratio of $v_{\text {fall }}$ to shear velocity $\left(U_{*}\right)$. Yalin (1977) presents a series of curves describing the distribution of particles under different rouse numbers $\left.\left(\hat{\mathrm{s}}=2.5 \cdot v_{\text {fall }}\right) / U_{*}\right)$. Calculating $U_{*}$ as $\sqrt{\tau}$, mean $\hat{\mathrm{s}}$ for particle size classes used in this study were $0.032,0.024,0.002$, and 0.001 for MPOM, FPOM, VFPOM, and diatoms, respectively. Using Yalin's (1977) curves, these numbers predict a nearly homogeneous distri- 
bution of diatoms and VFPOM with depth and a slight, downward skewing in the distribution of FPOM and MPOM. These distribution predictions provide additional evidence for our suggestion that particle size begins to influence $v_{\text {dep }}$ at particle diameters $>50 \mu \mathrm{m}$.

Controls on fine organic particle $\mathrm{v}_{\text {dep }}$ and $\mathrm{S}_{P}$-Although the preceding analysis suggests that the differential distribution of particles within the water column (as effected by $\left.v_{\text {fall }}\right)$ may account for the subtle differences we observed in $v_{\text {dep }}$ between particle sizes and types, it remains unclear what mechanisms are primarily responsible for organic particle deposition in natural channels. The conservative behavior of $v_{\text {dep }}$ across detrital size classes extends to particles of varying types as well. Diatoms, which had the lowest predicted fall velocity (0.017), deposited at a rate similar to FPOM and VFPOM in Upper Bloomington Creek. Reported values of $v_{\text {dep }}$ for corn pollen (Miller and Georgian 1992; Webster et al. 1999) and bacteria (Hall et al. 1996) also were within the range reported here (Fig. 4., gray circles). We submit that the available data indicate that $v_{\text {dep }}$ is effectively uncoupled from $v_{\text {fall }}$ for particles with diameters $<100 \mu \mathrm{m}$ and that specific stream configurations are characterized by a base deposition rate that lies between 0.01 and $1.0 \mathrm{~mm} \mathrm{~s}^{-1}$ (Fig. 4). If gravitational settling is not an important depositional pathway, yet deposition continues to occur, what are the mechanisms responsible for seston deposition in streams?

A variety of depositional pathways other than gravitational settling have been suggested in the literature. These mechanisms include (1) the advective transport of POM into sediment interstices (McConnell-Boyer et al. 1986; Packman et al. 2000), (2) the adhesion of particles to benthic biofilms (Bouwer 1987), and (3) the capture of seston by filter-feeding invertebrates (McCullough et al. 1979). In some streams the retention of suspended POM within macrophyte beds may also be important (e.g., Koetsier and MacArthur 2000).

Advection of solutes into the streambed has been well documented (Bencala and Walters 1983; Triska et al. 1989). In comparison, particulate movement within sediments is poorly understood, although some notable exceptions exist. For example, Metzler and Smock (1990) demonstrated that POM is transported into subsurface sediments under mean discharge conditions in a sandy bottom stream. In assessing hyporheic respiration rates and FPOM distribution, Pusch (1996) concluded that a continuous supply of organic matter must be made available to hyporheic sediments through hydrological transport. Brunke (1999) provided support for Pusch's conclusion by demonstrating that fine particles can be transported by interstitial throughflow to depths in excess of $1 \mathrm{~m}$ below the water-streambed interface. Our observation that $A_{\mathrm{S}} / A$ was most closely associated with variation in $v_{\text {dep }}$ is consistent with interstitial filtration as a mechanism of particle deposition.

Adhesion of organic particles to biofilms also has been demonstrated (Bouwer 1987). Biofilm abundance estimates are not available in the present study. However, if areal standing stock of epilithic biofilms were equivalent across experimental locations, then we would expect a positive association to exist between $v_{\text {dep }}$ and hydraulic radius $(R)$. In this study, we observed a significant, negative relationship between FPOM $v_{\text {dep }}$ and $R$ and a similar, but insignificant, relationship between VFPOM $v_{\text {dep }}$ and $R$ (Fig. 3). Further research will be required to examine whether particle deposition is influenced simply by the presence of a biofilm surface or whether biofilm mass per unit area contributes to particle "trapping."

Capture of seston by filter-feeding invertebrates is another pathway by which seston can be transferred to streambeds. A variety of studies have indicated that filter feeding can reduce seston concentration in streams (e.g., Maciolek and Tunzi 1968). However, McCullough et al. (1979) used ingestion studies, population estimates, and seston standing stock measurements to determine that net spinning caddisflies removed $\approx 0.01 \%$ of seston per meter under high-flow conditions at Deep Creek (same reach used in the current study). This removal rate translates to $v_{\text {dep }}=0.015 \mathrm{~mm} \mathrm{~s}^{-1}$, which is $\sim 25$ times less rapid than observed in the present study. For further information on the influence of filter-feeding invertebrates in these streams, see Monaghan et al. (in press).

It should be acknowledged that depositional mechanisms are not necessarily independent. For example, fine organic particles are likely to be exposed to biofilms and gravitational settling as they enter interstitial environments. Although the mechanisms discussed above may be sensitive to particle size, they are likely to be less so than gravitational settling and may combine to establish a minimum deposition rate toward which field deposition rates approach as particle $v_{\text {fall }}$ decreases. Ultimately, we suspect that a combination of processes is responsible for particle flux between the water column and the benthos and the retention of particles therein.

Particle transport distance-Particle transport distance $\left(S_{\mathrm{P}}\right)$ represents the longitudinal movement of material within streams. $S_{\mathrm{P}}$ values reported in this research span the range of those previously reported for various particle sizes and types. Hall et al. (1996) used fluorescently labeled bacteria to estimate transport distances of 78 and $83 \mathrm{~m}$ in two experiments in a North Carolina headwater stream. Miller and Georgian (1992) used a seston analog (corn pollen, $88 \mu \mathrm{m}$ ) to calculate transport distances of 120-190 m in New York streams. Minshall et al. (2000) estimated FPOM (53-106 $\mu \mathrm{m}$ ) transport distances ranging from 7 to $1,000 \mathrm{~m}$ using ${ }^{14} \mathrm{C}$-labeled natural detritus in first- to third-order Idaho streams. In an investigation of nitrogen dynamics in the $\mathrm{Ku}-$ parak River, Wollheim et al. (2001) determined that the $S_{\mathrm{P}}$ of suspended particulate organic nitrogen varied from 113 to $9,650 \mathrm{~m}$.

Unlike $v_{\text {dep }}, S_{\mathrm{P}}$ is the product of both deposition and transport characteristics of streams. Because deposition varied little among particle sizes and types, it follows that $S_{\mathrm{P}}$ of FPOM and VFPOM would react similarly across a hydrologic gradient, and generally speaking, this is what we observed. Increasing stream size (as reflected in $u, h, A, Q_{\mathrm{w}}$, and $Q$ ) tended to be associated with increasing $S_{\mathrm{P}}$ for both size classes investigated in this study (Table 4). The pattern of variability observed in POM transport distance leads to two general conclusions: (1) variability between experimental locations was greater than variability between size classes. and (2) because of limited variability in $v_{\text {dep }}, S_{\mathrm{P}}$ was 
largely a function of flow characteristics (e.g., $Q_{\mathrm{W}}$ ). Wollheim et al. (2001) also demonstrated a close association between stream size (as $Q$ ) and $S_{\mathrm{p}}$. In their analysis, the relationship between $S_{\mathrm{P}}$ and $Q$ was similar to the relationship between $Q_{\mathrm{w}}$ and $Q$ such that $S_{\mathrm{P}} \sim Q^{0.57}$ and $Q_{\mathrm{W}} \sim Q^{0.54}$. Based on these power functions, Wollheim et al. (2001) concluded that particle transport distance in the Kuparak River is primarily controlled by variation in hydrologic variables (e.g., water depth and velocity) rather than longitudinal changes in $v_{\text {dep }}$. In our research, $Q_{\mathrm{w}} \sim Q^{0.63}$, whereas FPOM $S_{\mathrm{P}} \sim Q^{0.94}$ and VFPOM $S_{\mathrm{P}} \sim Q^{0.97}$, suggesting that variation in $v_{\text {dep }}$ causes $S_{\mathrm{P}}$ to increase more rapidly with increasing $Q$ than would be expected from the relationship between $Q$ and $Q_{\mathrm{w}}$.

It has been postulated that the longitudinal movement of fine organic particles is an important mechanism linking upstream and downstream reaches of streams (Vannote et al. 1980). The results of this study indicate that single transport events occurring in first- and second-order streams are short relative to total river length. If FPOM links headwaters to lower stream reaches, our results indicate that multiple deposition-resuspension events (saltation) must occur during the period of time a specific particle resides within the stream network. If so, benthic communities have the opportunity to strongly influence the quantitative and qualitative characteristics of stream seston. The strength of this influence will depend upon (1) the number of deposition events that occur during a particle's "lifespan" in the stream, (2) the length of time a particle resides on or in the benthos per deposition event (i.e., benthic turnover time), and (3) the biological processes active at the site of deposition (e.g., invertebrate feeding, microbial decomposition). Cushing et al. (1993) reported that the majority of deposited particles (98\%) were resuspended within $24 \mathrm{~h}$ of deposition at Smiley Creek. However, a rigorous assessment of the role of fine organic particles in the longitudinal linkage of streams will require assessing the decomposition dynamics of fine organic particles (sensu Webster et al. 1999) and further study of the retention dynamics of benthic POM.

\section{Conclusions}

Particles with higher fall velocities were deposited at higher rates than those with low fall velocity. However, the magnitude of the difference between size classes was far less than that expected from particle characteristics. We argue that the particle size classes investigated in this study are near the cusp in the size class continuum where fall velocity becomes important in determining deposition rates in these streams. We suggest that attributes of the benthos (e.g., hyporheic exchange, biofilm characteristics) are as or more important than water column or particle characteristics in controlling seston deposition in streams. Refining our understanding of particle dynamics will require additional studies using smaller or larger particles than those investigated here. In addition, experiments that isolate specific pathways of deposition are necessary to advance our theoretical understanding of fine organic particle deposition in streams and possibly other turbulent habitats.

\section{References}

Bencala, K., And R. Walters. 1983. Simulation of solute transport in a mountain pool-and riffle-stream: A transient storage model. Water Resour. Res. 19: 732-738.

Bouwer, E. J. 1987. Theoretical investigations of particle deposition in biofilm systems. Water Resour. Res. 21: 1489-1498.

BRUNKe, M. 1999. Colmation and depth filtration within streambeds: Retention of particles in hyporheic interstices. Int. Rev. Hydrobiol. 84: 99-117.

Cordoba-Molina, J. F., R. R. Hudgins, and P. L. Silveston. 1978. Settling in continuous sedimentation tanks. Proceedings of the American Society of Civil Engineers. J. Environ. Eng. Div. 104: 1263-1275.

Cushing, C. E., G. W. Minshall, and J. D. Newbold. 1993. Transport dynamics of fine particulate organic matter in two Idaho streams. Limnol. Oceanogr. 38: 1101-1115.

Denny, M. W., And M. F. Shibata. 1989. Consequences of surfzone turbulence for settlement and external fertilization. Am. Nat. 134: 859-889.

Dobbins, W. E. 1944. Effects of turbulence on sedimentation. Trans. Am. Soc. Civ. Eng. 109: 626-656.

Draper, N. R., AND H. SMith. 1966. Applied regression analysis. John Wiley.

ECKMAN, J. E. 1990. A model of passive settlement by planktonic larvae onto bottoms of differing roughness. Limnol. Oceanogr. 35: 887.

Einstein, H. A., AND R. B. KRone. 1962. Experiments to determine modes of cohesive sediment transport in salt water. J. Geophys. Res. 67: 1450-1461.

Hall, R. O., JR., C. L. Peredney, and J. L. Meyer. 1996. The effect of invertebrate consumption on bacterial transport in a mountain stream. Limnol. Oceanogr. 41: 1180-1187.

HART, D. R. 1995. Parameter estimation and stochastic interpretation of the transient storage model for solute transport in streams. Water Resour. Res. 31: 323-328.

Harvey, J. W., AND B. J. Wagner. 2000. Quantifying hydrologic interactions between streams and their subsurface hyporheic zones, p. 4-40. In J. B. Jones and P. J. Mulholland [eds.], Streams and ground waters. Academic Press.

KoEtSIER, P. AND J. V. MACARTHUR. 2000. Organic matter retention by macrophyte beds in 2 southeastern USA, low-gradient, headwater streams. J. N. Am. Benthol. Soc. 19: 633-647.

MacioleK, J. A., AND M. G. TunZI. 1968. Microseston dynamics in a simple Sierra Nevada lake-stream system. Ecology 49: 6075.

McConnell-Boyer, L. M., J. R. Hunt, And N. Stair. 1986. Particle transport through porous media. Water Resour. Res. 22: 1901-1921.

McCullough, D. A., G. W. Minshall, And C. E. Cushing. 1979. Bioenergenics of lotic filter-feeding insects Simulium spp. (Diptera) and Hydropsyche occidentalis (Trichoptera) and their function in controlling organic transport in streams. Ecology 60: $585-596$.

McNair, J. N., J. D. Newbold, AND D. D. Hart. 1997. Turbulent transport of suspended particles and dispersing benthic organisms: How long to hit the bottom? J. Theor. Biol. 188: 29-52.

Metzler, G. M, AND L. A. SMOck. 1990. Storage and dynamics of subsurface detritus in a sand-bottomed stream. Can. J. Fish. Aquat. Sci. 47: 588-594.

Miller, J., AND T. GeORgian. 1992. Estimation of fine particle transport in streams using pollen as a seston analog. J. N. Am. Benthol. Soc. 11: 172-180.

Minshall, G. W., R. C. Petersen, K. W. Cummins, T. L. Bott, J. R. Sedell, C. E. Cushing, And R. L. Vannote. 1983. Inter- 
biome comparison of stream ecosystem dynamics. Ecol. Monogr. 53: 307-322.

, S. A. Thomas, J. D. Newbold, M. T. Monaghan, and C. E CUSHING. 2000. Physical factors influencing fine organic particle transport and deposition in streams. J. N. Am. Benthol. Soc. 19: 1-17.

Monaghan, M. T., S. A. Thomas, G. W. Minshall, J. D. NewBOLD, AND C. E. CusHING. 2001. The influence of filter-feeding benthic macroinvertebrates on the transport and deposition of particulate organic matter and diatoms in two streams. Limnol. Oceanogr. 46: 1091-1099.

Morrice, J. A., H. M. Valett, C. N. Dahm, and M. E. Campana. 1997. Alluvial characteristics, groundwater-surface water exchange, and hydrologic retention in headwater streams. Hydrol. Process. 11: 253-267.

Naiman, R. J, AND J. R. Sedell. 1979. Characterization of particulate organic matter transported by some Cascade Mountain streams. J. Fish. Res. Board Can. 36: 17-31.

Newbold, J. D., J. W. Elwood, R. V. O'Neill, and W. Van WinKLE. 1981. Nutrient spiraling in streams: The concept and its field measurement. Can. J. Fish. Aquat. Sci. 38: 860-863.

- P. J. Mulholland, J. W. Elwood, and R. V. O'Neill. 1982. Organic carbon spiraling in stream ecosystems. Oikos 38: $266-272$.

, C. E. Cushing, and G. W. Minshall. 1991. Use of ${ }^{14} \mathrm{C}-$ label to study fine particulate organic matter dynamics in flowing water, p. 493-501. In R. A. Baker [ed.], Organic substances and sediments in water, v. 2. Processes and analytical. Lewis Publishers.

O'Melia, C. R. 1980. Aquasols: The behavior of small particles in aquatic systems. Environ. Sci. Technol. 14: 1052-1060.

Packman, A. I., N. H. Brooks, And J. J. Morgan. 2000. A physicochemical model for colloid exchange between a stream and a sand streambed with bed forms. Water Resour. Res. 36: 2351-2361.

PusCH, M. 1996. The metabolism of organic matter in the hyporheic zone of a mountain stream, and its spatial distribution. Hydrobiologia 323: 107-118.

Reynolds, C. S., M. L. White, R. T. Clarke, and A. F. Marker. 1990. Suspension and settlement of particles in flowing water:
Comparison of the effects of varying water depth and velocity in circulating channels. Freshw. Biol. 24: 23-34.

Rouse, H. 1937. Modern conceptions of the mechanics of fluid turbulence. Trans. Am. Soc. Civ. Eng. 102: 436-505.

Sмiтh, I. R. 1982. A simple theory of algal deposition. Freshw. Biol. 12: 445-449.

Stream Solute Workshop. 1990. Concepts and methods for assessing solute dynamics in stream ecosystems. J. N. Am. Benthol. Soc. 9: 95-119.

Triska, F. J., V. C. Kennedy, R. J. Avanzino, G. W. Zellweger, AND K. E. BENCALA. 1989. Retention and transport of nutrients in a third-order stream in northwestern California: channel processes. Ecology 70: 1877-1892.

Vannote, R. L., G. W. Minshall, K. W. Cummins, J. R. Sedell, AND C. E. Cushing. 1980. The river continuum concept. Can. J. Fish. Aquat. Sci. 37: 130-137.

Wallace, J. B., D. H. Ross, and J. L. Meyer. 1982. Seston and dissolved organic carbon dynamics in a southern Appalachian stream. Ecology 63: 824-838.

Webster, J. R., and J. L. Meyer [eds.]. 1997. Stream organic matter budgets. J. N. Am. Benthol. Soc. 16: 3-161.

, E. F. Benfield, S. W. Golladay, R. F. KazmierczaK, W. B. Perry, and G. T. Peters. 1988. Effects of watershed disturbance on stream seston characteristics, p. 279-294. In W. T. Swank and D. A. Crosley [eds.], Forest hydrology and ecology at Coweeta. Springer-Verlag.

- E. F. Benfield, T. P. Ehrman, M. A. Schaeffer, J. L. TANK, J. J. Hutchens, AND D. J. D'Angelo. 1999. What happens to allochthonous material that falls into streams? A synthesis of new and published information from Coweeta. Freshw. Biol. 41: 687-705.

Wetzel, R. G. 1983. Limnology. Saunders College Publishing.

Wolfinbarger, L., AND M. P. Crosby. 1983. A convenient procedure for radiolabeling detritus with $\left({ }^{14} \mathrm{C}\right)$ dimethylsulfate. J. Exp. Mar. Biol. Ecol. 67: 185-198.

WOLlHEIM, W. M., AND OTHERS. 2001. Influence of stream size on ammonium and suspended particulate nitrogen processing. Limnol. Oceanogr. 46: 1-13.

Yalin, M. S. 1977. Mechanics of sediment transport. Pergammon.

Received: 6 January 2000

Accepted: 31 March 2001

Amended: 27 April 2001 